\title{
CV-Muzar Using a Multiagent System for Group Formation
}

\author{
Ana Carolina Bertoletti De Marchi ${ }^{1}$, Márcia Cristina Moraes ${ }^{2}$, \\ and Cristiane Durigon Testa ${ }^{1}$ \\ ${ }^{1}$ Universidade de Passo Fundo, Curso de Ciência da Computação. BR 285, \\ Bairro São José, Passo Fundo, Brasil \\ ${ }^{2}$ Pontifícia Universidade Católica do Rio Grande do Sul, \\ Instituto de Informática. Av. Ipiranga, 6681 - prédio 50, Porto Alegre, Brazil \\ carolina@upf.br, mmoraes@inf.pucrs.br, \\ cristiane_dteyahoo.com.br
}

\begin{abstract}
The purpose of this paper is to present two agents' societies responsible for group formation (sub-communities) in CV-Muzar (Augusto Ruschi Zoobotanical Museum Virtual Community of the University of Passo Fundo). The first is a static society that intends to investigate the groups in the CVMuzar. The second is a dynamical society that will analyze the existing groups and look for participants that have common subjects in order to constitute a subcommunity. The formation of sub-communities is a new module within the CVMuzar that intends to bring the participants together according to two scopes: similarity of interests and knowledge complementarities.
\end{abstract}

Keywords: Virtual learning communities, multi-agent systems, informal learning.

\section{Introduction}

Over the last years, we were able to notice people's increasing interest in making use of the available resources on the Internet to improve their knowledge and interact with others. The virtual learning communities have proved to be favorable environments for this practice, because their participants are related to the construction of knowledge common goals. According to Pallof and Pratt [1] the virtual learning communities are dynamical components that emerge when a group of people shares certain practices, they are interdependent, make joint decisions, identify themselves with something larger than the total sum of their individual relationships and establish a long term commitment with the well being of all participants.

Group formation inside virtual learning communities is interesting, because group learning aims to develop and to improve individual skills for the use of knowledge, to accept responsibilities for the individual and the group learning process; to develop the abilities of reflecting about its own suppositions expressing its ideas to the group and to develop social and group abilities.

This paper presents information about the formation of groups within the CVMuzar (Augusto Ruschi Zoobotanical Museum Virtual Community of the University 
of Passo Fundo). The groups are called sub-communities and are formed from two concepts: interest similarity and knowledge complementarities.

Two agents' societies were used in order to automate the sub-communities construction. The first society is static, and intends to investigate descriptive information about groups in the CV-Muzar. The second society is a dynamical society that will analyze the existing groups and look for participants that have common subjects in order to constitute a sub-community.

The static society is based on search algorithms to collect information for the establishment of sub-communities. Such information includes the group profile, concentration area of content of the possible participants as well as their interest area.

The dynamical society is based on the Dependence-Based Coalition Model, established on the Social Reasoning Mechanism and Contractual Network, based on Sichman's Economic Market Theory [2].

The paper is organized in five sections. Following this introduction, the second section discusses concepts of virtual learning communities, especially the CV-Muzar. The third section presents the group formation proposal for CV-Muzar. The fourth section describes some initial tests and the fifth section describes some final considerations and future works.

\section{Virtual Learning Communities and CV-Muzar}

The virtual learning communities have proved, recently, to be complex environments, which require a development and proper tools to fulfill their needs.

These environments are characterized as informal learning environments as the CV-Muzar, where the online communication is the main form of knowledge exchange through the use of synchronous or non-synchronous tools. In CV-Muzar the informal learning is stimulated by the use of learning objects repositories, the use of communication tools and the production of learning objects by the visitors.

The CV-Muzar (http://inf.upf.br/comunidade) was developed with the main purpose of involving more the museum visitors, making them part of the experience, putting an end to the passive receiver of the expositive speech that was established unilaterally [3]. Besides that the museum aims to amplify the communication channels, offering the public access to a vast amount of information produced and kept by their staff.

For the environment development we made use of the concept of virtual communities to promote the exchanges among the visitors and the Learning Objects (LOs). The LOs favor the museum communicative expansion, once they enable the creation of simple and small didactic materials, which can easily be used outside the museum environment.

The environment has a vast collection of materials built over nearly three years of use. The available information is organized into learning objects (LOs) that comprise materials developed for the displays, materials kept in the museum and users' productions. Due to these productions, the environment is in ongoing update and growth.

To build the basic elements of the environment, we assume that the essence of a museum is informal learning. Our goal is to provide an environment that favors lifelong learning in a casual and spontaneous way, without the existence of a strict and 
curricular structure. The objective is to create stronger bonds among the participants, bringing them near.

In order to provide CV-Muzar participants with the possibility of deepening discussions related to specific subjects, this paper presents the module of subcommunities formation, which allows any participant to create a new group to deal with specific subjects.

To create the sub-communities the multiagent systems technology was used, through the creation and development of two societies: one static and the other dynamic. In the next section function of these societies will be explained in detail.

\section{Sub-communities Formations Assisted by Multiagent Systems (MAS)}

Over the years, we have seen an increase in the use of groups in the execution of the most varied kinds of activity. In the educational area, the interest in the group formation starts in the 1960's, however, the first works on the subject appeared in the forties, when researchers studied groups based on the behavior of their members. The use of groups got a stronger impulse from Vygotsky's [5] work, because his theories were based on the experience that through discussion there is a knowledge consolidation and the findings of new solutions.

Some important information that must be considered in the understanding of groups formation, are their objective and subjective limits [6]. The objective limits of a group can be, the size of the group and the duration and the space that will be reserved for the execution of an activity in the group. Some researchers believe that the minimum number of members should be three, in order to have some group behavior. The subjective limits can be exemplified by the boundaries of the activity that is being developed by the group, that is, what the group must or must not to do.

The sub-community term represents the formation of small groups within the CVMuzar. In these groups discussions will take place about subjects of common interest among the participants. A sub-community can be created by any participant previously registered in the environment and its formation (constitution of its components) occurs considering two needs:

- interest similarity: groups are formed by participants that have similar profiles;

- knowledge complementarities: groups are formed by participants that are gathered to accomplish complex tasks which require the composition of abilities for solving problems.

The sub-communities formation is undertaken through a multiagent system, composed by two types of societies:

- static: aims to investigate the information about groups, and

- dynamic: aims to analyze the existing groups and try to look for participants that have similar content to participate.

The static society, named Investigating Society of Sub-Community (SIS-C), uses search algorithms and the dynamic society is developed based on the Dependence-Based 
Coalition Model, founded on the Social Reasoning Mechanism and Contractual Network, based on Sichman's Economic Market Theory [2].

A MAS is a society formed by agents that coexist in the same environment and interact in order to accomplish a common goal [7]. The MAS area studies the behavior of an organized group of independent agents that cooperate in solving problems, which are beyond each individuals' capacities.

The next paragraphs explain how the Investigating Society of Sub-Community (SIS-C) and Investigating Society of Participants (SIP) work. Figure 1 shows the high level interaction between SIS-C and SIP.

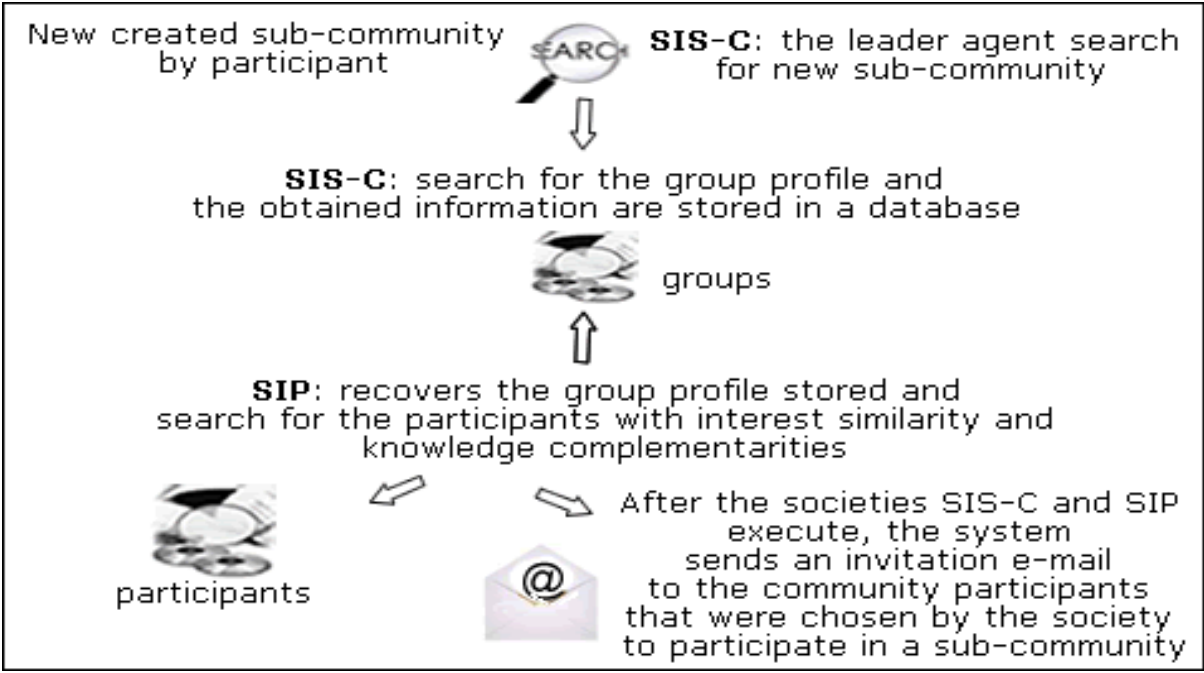

Fig. 1. High level interaction between SIS-C and SIP

The Investigating Society of Sub-Community (SIS-C) is characterized as a kind of static organization, because the roles that each agent will play within the society are already pre-defined like, for instance, the definition of each agent's role within the society. The roles that an agent can execute inside a society are a service provider agent and a leader agent. The service provider agent is the one responsible to provide service to others. The leader agent is responsible to find out which services agents can fulfill the necessary requirements to execute a task. Figure 2 illustrates the functioning of the SIS-C society and agents' communication. This functioning is illustrated through JADE platform.

As we can observe in figure 2 , one of the society agents is defined as the leader agent, regardless of his knowledge. He is so-called because he will have the role to pass the required tasks by the environment to the other SIS-C society agents.

The leader agent gets information that a new group was created and he needs to investigate this group's profile in order to look for the participants who have interest in join the new group. At this moment, the process of tasks distribution is started. The leader agent checks a list of agents that have the capacity to fulfill the requirements of the search for the group profile, for instance, if agent $\mathrm{A}$ has the capacity to develop 
the proposed task "T1". The leader agent asks agent A if he is available to fulfill the requirement. If so, there is a direct communication between the leader agent and the service deliverer.

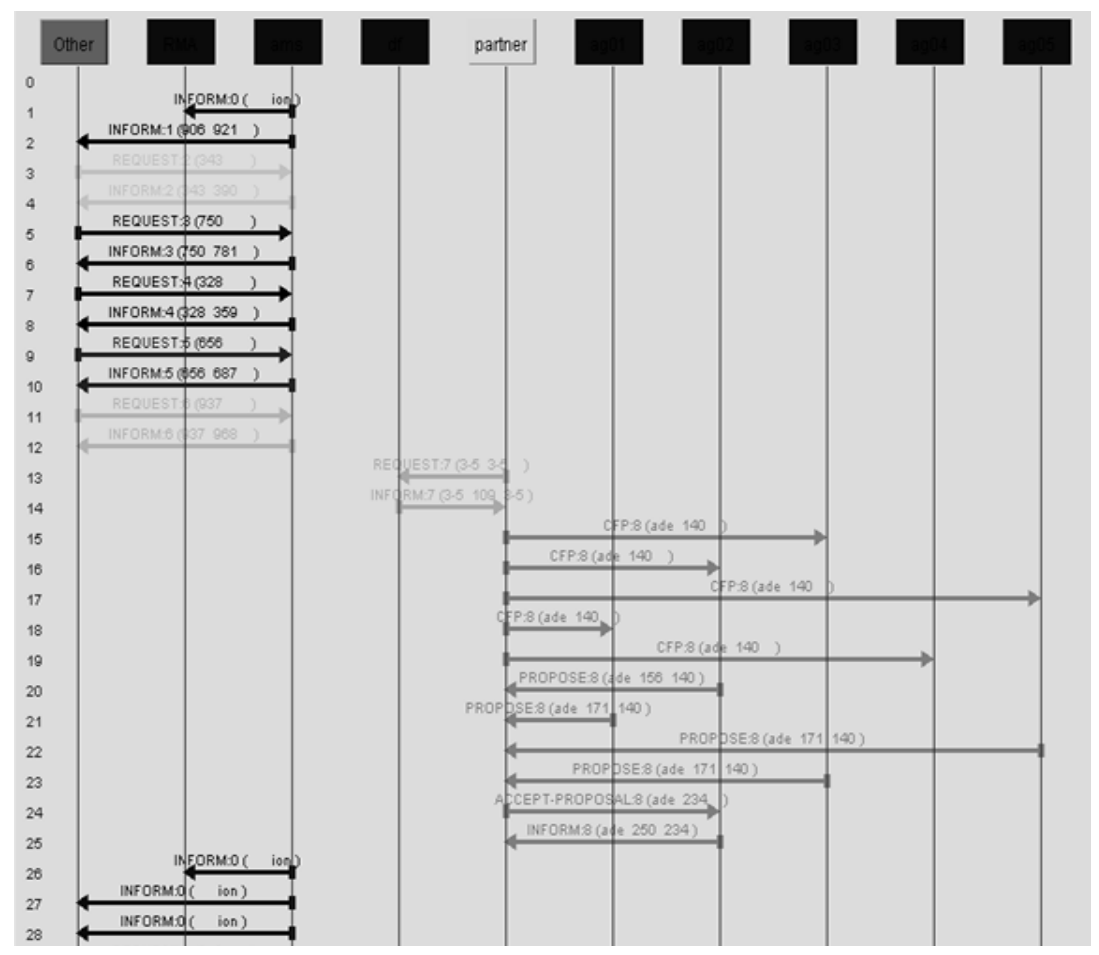

Fig. 2. Functioning of the SIS-C society presented through JADE platform

As mentioned before, the first task that will be accomplished by the SIS-C, specifically by the leader agent is the search for group profile. This search is composed by the following steps:

1. to verify all the information provided by the group coordinator. These information includes objectives, keywords, area of interest and communication tools used by the group;

2. to verify if the proposed profile is not similar to any other existing profile;

3. to verify the group's central theme, if it is in accordance with the environment central idea that is natural sciences.

If all the listed requirements above are in accordance, the other activities are carried out; otherwise, the leader agent sends a message to the group coordinator advising him about the items that must be reviewed. The other activities are to search within the concentration area for the sub-communities and to search, within the interest area, for possible participants. 
The option to use a leader agent enables the interoperability among the heterogeneous agents that are part of the society. After the communication cycle among the SIS-C society agents is over, the obtained information are stored in a database for a possible migration of some static society agents to the dynamical society. Thus, if it is necessary to migration, the coalition formation can occur for the search of participants that have profile similar to the group.

With the first part of information about the stored groups in a database, it is necessary to obtain information about the participants in order to accomplish the formation of the sub-communities. This task is carried out by the Investigating Society of Participants.

The Investigating Society of Participants is characterized as the dynamical type, because in this kind of organization there is the need of social interaction, that is, the agents must be able to gather and interact in order to achieve their local goals, whose combination occasionally results in the resolution of the community global goal.

The option to use the Dependence-Based Coalition model (DBC) for the dynamical organization is due to the fact that this is a model where there is cooperation and the communication between the agents is the main means for the accomplishment of the tasks. If the agent that integrates the society does not have the autonomy to carry out a certain activity, another member who can help is required. This way, over the time the agents improve their knowledge about other agents.

The formation of coalitions on the DBC model occurs in the following way: (the steps of the model are written in the form of an example of a procedure that occurs in the society):

1. Choice of a goal: an agent Ag1 chooses a certain goal to be achieved. In case there is no longer a goal, agent Ag1 does not try to form coalitions anymore. The choice of a goal can be the search for participants that have interest in discussing issues about "Environment Pollution". The goal is always chosen based on the formed groups.

2. Choice of a plan: supposing that Ag1 chose the G1 goal, the next step is to choose a plan to accomplish it. As the agent can have more than one plan for the same goal, the choice of the plan is based on the notion of feasible plan. In case there are no more plans, step one is resumed. Based on the participants' profile, agent Ag1 can have several plans for this objective and this way he chooses one that can be used. If Ag1 finds the plan worthwhile, he executes the analysis of the plan actions.

3. Analysis of the plan actions: once a plan is chosen, Ag1 analyses its objective situations concerning $\mathrm{G} 1$, in case the situation is independent or dependent. If the situation is independent, $\mathrm{Ag} 1$ is considered independent to accomplish that objective and this way does not need cooperation from any other agents. In this context, Ag1 can commence his activities to achieve his goal G1 with no need to form coalition. In the dependence situation, however, Ag1 cannot initiate the execution of his plan immediately, for he first needs to find an agent that accomplishes the action he does not know how to execute.

4. Choice of the partner: Through the social resolution mechanism, Ag1 considers his relationships and dependence situations with the other agents related to G1 and through the pre-established criterion, Ag1 chooses the 
best possible partners. In case there are not possible partners for the actual action, Ag1 chooses a new plan to achieve G1 returning to step 2.

5. Coalition formation between the agents: once the best possible partner is chosen, here so-called Ag2, Ag1 will send it a coalition proposal, which can contain the following proposals:

- Ag2 accepts the proposal and the coalition is formed. From this moment on, the works to solve G1 are started. At the end of this process, if the actions were accomplished correctly, G1 is considered concluded and an invitation is sent to the participants that have a profile similar to the group's to participate; and Ag1 can return to step 1;

- Ag2 refuses the proposal and in this case Ag1 tries respectively to find another partner, returning to step 4. The proposal refusal by Ag2 can occur through the following factors:

- Ag1 misunderstood Ag2, probably for having incorrect or incomplete information about Ag2. In this case, Ag2 informs such information to $\mathrm{Ag} 1$, and $\mathrm{Ag} 1$ can review his opinion about $\mathrm{Ag} 2$.

- Ag2 did not find the proposal interesting for his goals.

The MAS uses the rules previously described to search for participants for a subcommunity. Thus, the sub-community coordinator does not need to worry about finding partners for his group. He focuses on cheering up the group and encouraging the creation of discussions that enrich the knowledge.

The program code below shows the algorithm that will calculate the total number of messages in a society with $n$ agents to establish presentation communication and to search for a partner, for a total number of cycles $\mathrm{g}$. The algorithm is based on a previous analysis of the process within the CV-Muzar.

At each cycle, all the communication between the agents takes place through the messages exchanges. The active agent sends messages of coalition proposal until he finds a partner or until there are no possible partners. The possible partner always responds to the coalition proposal sending a message of acceptance or review. When the active agent gets an acceptance message, he sends a coalition message establishing the agreement with the partner agent. If no partner is found the coalition message is not sent. Thus, considering a society with $n$ agents, where $m$ agents can accomplish the desired action, and coalition proposal messages are sent to $k$ agents (means that $\mathrm{k}-1$ agents sent messages of refusal or review), the total number of sent messages in each cycle is: Scycle $=2 \mathrm{~m}$ in case it didn't find any partner; Scycle $=2 \mathrm{k}+1$, where 0 $<\mathrm{k}<=\mathrm{m}$ and Scycle $=0$ if the agent is independent.

Example of an algorithm that calculates the total number of messages in a society

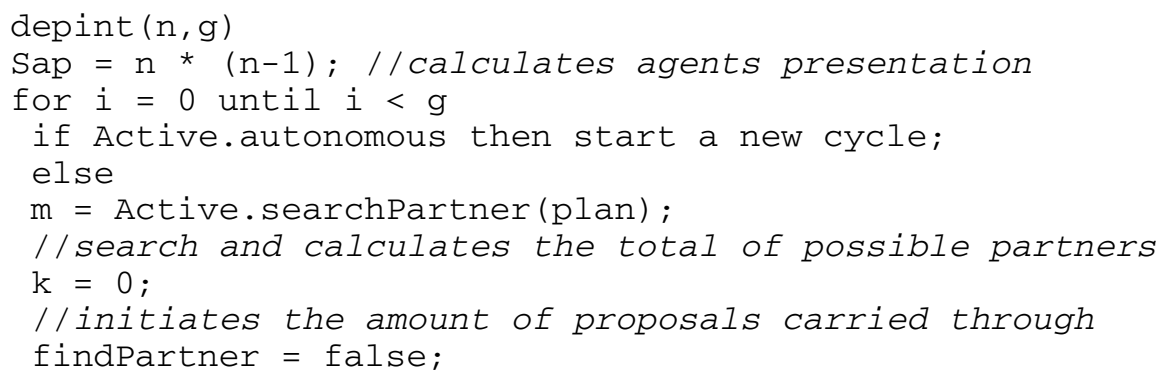




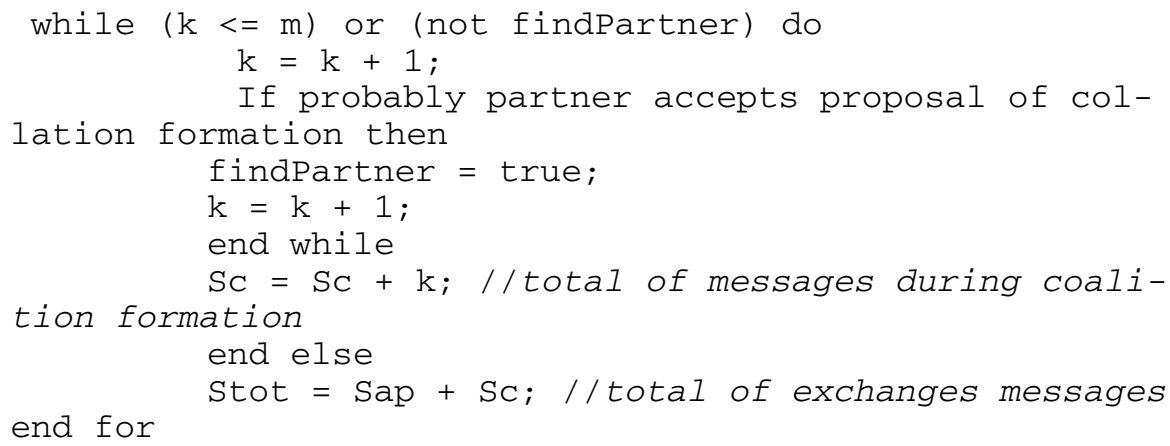

Now, considering a $g$ cycles competition, the total number of exchanged messages between the agents after all the accomplished cycles $\left(\mathrm{S}_{\mathrm{DBC}}\right)$ is:

$$
\mathrm{S}_{D B C}=\mathrm{S}_{\text {presentation }}+\sum \underset{\mathrm{i}=1 \mathrm{i}=1}{\mathrm{gg}} \mathrm{S}_{\text {cycle }}=n(n-1)+\sum \mathrm{S}_{\text {cycle }},
$$

where: Scycle $=2 \mathrm{~m}$ in case it didn't find any partner; Scycle $=2 \mathrm{k}+1$, where $0<\mathrm{k}<=$ $\mathrm{m} ;$ Scycle $=0$ if the agent is independent.

These societies were implemented using the platform JADE and they were integrated to CV-Muzar, which is implemented in PHP. After the societies SIS-C and SIP execute, the system sends an invitation e-mail to the community participants that were chosen by the society to participate in a sub-community. The participants can accept the invitation or not.

\section{Initial Tests}

As a base of tests for the MAS, a simple experiment in the formation module of subcommunities within the CV-Muzar was carried out, with the participation of some trainees from Muzar. Fifteen people related to the museum were invited, trainees, professors and staff members. The participants were divided into two different groups. The first group received a small description of how they should fill out the individual profile and the subject nominations for the groups' formation. This first group was instructed on how they should create the groups, key words and the relationship with the Topic Maps present in the CV-Muzar.

The second group was random, they didn't have any help filling out the individual profile as well as creating the groups. These, in turn, could create their profile according to their interest area and create groups that had interest in forming centralized discussions. Over the two weeks' tests, the participants were invited, through messages sent by e-mail, to take part in the sub-communities created by two groups. In all simulations carried out with the two groups, the MAS nominated correctly the sub-communities related to the participant's profile. However, it will be necessary to optimize the processing time of the information exchange between the agents on the Dependence-Based Coalition model, because it took a long time sending the invitations. 


\section{Final Considerations and Future Works}

As presented previously, the module for group formation is based on searches generated by the MAS, considering the Dependence-Based Coalition model In order to examine this model carefully and obtain a clearer analysis of the exchange flow when the dependence-based coalition process occurs, studies are being carried out to analyze the time that the society takes to process these data and send the message with the invitation to the participant. In this way, we chose to work with the Exchange Values theme, because in the Multiagent Systems area, more specifically in its applications to the social simulation, the matter of regulation of the interactions between the agents involved is quite important, since capturing the nature of the social relations depends, mostly, on the proper representation of the norms and social conventions.

The base for the interactions representation through the exchange values is Piaget's Sociological Theory [8], which states that the relationships among the individuals can be seen as services exchange among them, to which a range of exchange values are associated, being identified as social exchanges among the agents in a society.

For the application of the exchange values rule, the definition of an equation of exchange values is being studied, a mechanism of social reasoning and a set of internal structures to the agent for the storing and handling of these values.

For such procedure, Dimuro and Costa [9], present the proposal of creation of the exchange supervisor, a kind of leader agent as was defined in the Investigating Society of Participant, that is, a special agent capable of identifying the values involved in the exchanges accomplished by the agents and recommend them the accomplishment of new exchanges, with proper values so that the system has a balance.

On balance, socially speaking, it is understood that the system norms are followed. The agents, however, have their own personalities and, according to their goals, they can choose to follow the recommendations given by the supervisor or not. The mechanism used by the supervisor is shaped as a Markov's Decision Process (MDP), thus, at each instant he is able to recommend a set of exchanges, based on the current state of the values of the agents involved.

Acknowledgement. Thanks to Conselho Nacional de Desenvolvimento Científico e Tecnológico for the support through the edictal MCT/CNPq 15/2007 - Universal and Fapergs - Fundação de Amparo a Pesquisa do Rio Grande do Sul.

\section{References}

1. Palloff, R.M., Pratt, K.: Construindo Comunidades de Aprendizagem no Ciberespaço: Estratégias eficientes para salas de aula on-line [Building Online Learning Communities: Effective strategies for the virtual classroom], Artmed, Porto Alegre (2002)

2. Sichman, J.S.: Du Raisonnement Social chez les agents: Une Approche fondée sur la théorie de la dépendence. Thése de doctorat de 1'NPG, Grenoble, França (1995)

3. De Marchi, A.C.B.: Um ambiente de suporte a comunidades virtuais baseados em repositório de objetos de aprendizagem informal em museus [An environment supporting virtual communities based repository of informal learning objects in museums]. Thesis, PGIE, UFRGS (2005) 
4. Barker, T., Barker, J.: How Group Working Was Used to Provide a Constructive ComputerBased Learning Environment. In: The Fourth International Conference on Cognitive Technology, University of Warwick, United Kingdom, p. 203 (2001)

5. Vygotsky, S.L.: The Collected Works of L.S.Vygotsky. Plenum Press, NY (1987)

6. Jaques, P.A., Andrade, A.F., Moraes, M.C., Mora, M.: Uma Arquitetura de Agentes para a Análise Qualitativa da Interação em Ambientes de Educação à Distância [An Architecture for Agents for the Qualitative Analysis of Interaction in Distance Education Environments]. In: Simpósio Brasileiro de Informática na Educação, Maceió-Al (2000)

7. Wooldridge, M.: Introduction to MuliAgent Systems. Wiley, Chichester (2002)

8. Piaget, J.: Estudos sociológicos [Sociological studies]. Forense, Rio de Janeiro (1973)

9. Dimuro, G.P., Costa, A.C.R.: Exchange Values and Self-Regulation of Exchanges in MultiAgent Systems: the provisory, centralized model. In: Brueckner, S.A., Di Marzo Serugendo, G., Hales, D., Zambonelli, F. (eds.) ESOA 2005. LNCS, vol. 3910, pp. 75-89. Springer, Heidelberg (2006) 